\title{
Technical Education and Vocational Training for Sustainable Development
}

\author{
Shiba Bagale, Trainer \\ Community Development Programme, Training and Education Department, \\ Training Institute for Technical Instruction (TITI) \\ Sanothimi, Bhaktapur, Nepal \\ Email for correspondence: sbd@titi.org.np or shiba@kusod.edu.np
}

\begin{abstract}
Technical Education and Vocational Training is taken as an integral part of the national development. This has an important role in the national sustainable development. The knowledge, skills and attitudes are the overall aspects of the lifelong learning. In the context of Nepal, it has provided skills and jobs to many people who are away from the general education having several barriers within them. TEVT covers all the FIETS aspects of sustainability. This study has tried to highlight the major essence of the Technical Education and Vocational Training for the Sustainable Development of the nation. This paper has made an attempt to promote the TEVT through the perspectives of sustainable development. So it has highlighted on the aspects of education for sustainable development and the barriers behind it.
\end{abstract}

Key words: Technical Education, Vocational Training, Sustainable Development, barriers

\section{Introduction}

Education is a tool for sustainable development. It has different spheres of development including socio economic aspects. It also reflects upon the values that guides for actions. The major challenge in the world today is to find pathways of living and working sustainably, so that the reasonable needs and wants of people from all walks of life and in all countries can be satisfied. Thus over-exploiting the natural resources upon which all life depends that the ability of future generations to meet their needs and wants is threatened and we are still not realizing the fact.

Technical education is one of the cross cutting issues worldwide. Technical Education and Vocational
Training (TEVT) comprises formal, non-formal and informal learning for the world of work and the emphasis of the curriculum on the acquisition of employable skills and it will help for the fulfillment of the demand of skilled workers in the job market. People will learn knowledge and skills across a wide range of institutional and work settings and in diverse socio-economic contexts which prepare them for gainful employment and sustainable livelihoods. We see many developed countries are developed because of technical education. So the main focus of technical education is on the sustainable education. If the education is sustainable and it will helps in poverty reduction through economic benefit, then that education will help the individual and the nation. So 
skill based education is one of the demands of the present situation facing crisis on job market. Skills are vital for poverty reduction, economic recovery and finally will help for sustainable development.

UNESCO (2012) has also highlighted that TEVT is an integral part of the Education for All initiative and through its orientation towards the world of work and the acquisition of skills plays an essential role in promoting a country's economic growth and contributing to poverty reduction; ensuring the social and economical inclusion of marginalized communities. From this also we can clearly say that the main essence of TEVT is to promote the marginalized community through various skills and contribute to poverty reduction of the country.

Technical and vocational education, as an integral component of lifelong learning, has a crucial role to play in this new era as an effective tool to realize the objectives of a culture of peace, environmentally sound sustainable development, social cohesion and international citizenship. TVET can play an instrumental role in developing a new generation of individuals who will face the challenge of achieving sustainable socio economic development. It is important that vocational education can be a means to an end. It can be a tool for securing employment and sustainable development.

\section{Concept of Technical Education and Vocational Training}

In Nepal the concept of vocational education was developed from the very beginning but later with the establishment of Council for Technical Education and Vocational Training (CTEVT), formally got the shape. Vocational education is defined as any form of education whose primary purpose is to prepare persons for employment in recognized occupations (Okoro, 1993). So the most important aspect is for the employment.

Immaculate (2005) opined that vocational and technical education are leaving experience meant to be impacted to an individual systematically in order to get him/her adequately equipped for a good employment in a recognized occupation. Vocational education basically focuses on the enrichment of the capabilities that influence the effective psychomotor or cognitive domains of individual in readiness for entry into the world of work in order to satisfy their intrinsic and extrinsic values, work, and aspirations such that local and national needs would be met.

Vocational education moreover it focuses on the practical aspect of education on the acquisition of practical skills, attitudes, understanding and knowledge relating to occupation in various sectors of economic and social life. UNESCO (2004) identified the two major objectives of TVET as the urgent need to train the workforce for self employment and the necessity to raise the productivity of the informal sector. The concept is that development of skill enhances productivity and sustains competitiveness in the global economy. So vocational training can be concluded as an educational training designed systematically to enable an individual to acquire knowledge for the practical life and for the occupational career.

\section{TEVT for Sustainable Development} Education has been recognized internationally as fundamentally important to addressing the critical global challenges we all face. Sustainable development is one of the agendas of the Agenda 21 and also MDG has also great role for the sustainable development. There are various sectors for the sustainable development. Basically the infrastructures of development sustainability is necessary. Similarly, in the field of education too, sustainability is important and has great significance for the sustainable future.

The United Nations has also declared from 2005 to 2014, the Decade of Education for Sustainable Development. In the article 'Education for Sustainability: The role of education in engaging and equipping people for change' (2009) published by The Australian Research Institute in Education for Sustainability states, "The founding value of Education for Sustainable Development (ESD) is respect :respect for others, both present and future 
generations and respect for the planet and what it provides to us(eg. Resources, fauna and flora)"(p. 3). Thus, we can say that ESD challenges us to adopt new behavior and practices to secure our future.

Adebola (2007) defines sustainable development as a kind of development that can be initiated and managed properly in such a way as to give attention to continuity and preservation as people explore an explicit available resources for the enlargement of their existence. Creating a sustainable community requires that individuals and organizations have the knowledge, skills, values, capacity and motivation to respond to the complex sustainability issues they encounter in their personal and working lives. The environmental, social, cultural and economic implications are enormous and touch many aspects of life of the world's population. It also signifies that technical and vocational education will lead for sustainable future.

Technical and vocational education and training plays an essential role in improving the wellbeing of youths and communities. It increases productivity, empowers individual to become self reliant and stimulates entrepreneurship. Businesses are more willing to invest in a community with strong human resources. Chinwe, (2008) has also focused on skills development can therefore contribute to strengthening the social links of a community by promoting employment creativity and sustainable means of subsistence. Vocational education and job training program has been an integral part of national developments strategies in many societies because of the impact on human resources development, productivity, and economic growth.

The main aspect of technical education is to empower the youths. Basically it focuses on the poverty alleviation and the programs are targeted to the youths so that it would help to sustain them. Thus technical education is one of the aspects of sustainable development. So TVET can be a decisive instrument for youth to participate in the work force and to improve their living conditions and social status. Not only this, it will also help the people to be self employed and will increase the number of entrepreneurs. This will help for the development of a country. So these types of educations will merely help for the sustainable development.

Integrating Skill Development in Education for All (EFA) is one of the necessary aspects in the educational sector. Ensuring that all learning needs of young people and adults are met through equitable access to appropriate learning and life skills program is one of the six educations for all (EFA) goals established at the world education forum in Dakar 2000. Not only EFA through the general education, it could cover the TEVT sector too. It is one of the urgent needs to empower the youths for the sustainable achievement. TEVT program is one of the effective means for the disadvantaged group for the poverty alleviation.

According to Alam (2007), human capital theory has powerful influence on the analysis of labor market. Alam notes that investment in education and training produces benefit both to the individual and to society as a whole. So there is direct linkage of education and training in the national development. It eventually will help for the sustainable development. The return on investment for society will be a skilled workforce that will enable global competitiveness and economic growth, while the return of the individual will be a better career path, increased earning and a better quality of life.

TEVT has played significant role in promotion of education by ensuring the labor market and facilitates the access to social participants by teaching core skills. TEVT can be understood by the FIETS (Financial, Institutional, Environmental, Technological and Social) approach of sustainability. The people being trained on the technical education and vocational training can get employment and it will help them financially. If the adequate investment is done in this sector, then it would become part of green economy.

In the context of Nepal it could play an effective 
role for the people who are out of the mainstream of education and who are unable to spend a long tenure for the general education. TEVT is a good source for those who could complete the courses in short span and starts to earn. Therefore, expanding TVET in Nepal is integral for youth in crisis or post conflict situations, tackling poverty, and promulgating cultural inclusion for tolerant peaceful society. The youths through TVET education are encouraged to assume entrepreneurial position, as there is nothing that can surpass the effectiveness of hands on training. Thus it is one of the urgent needs for the sustainability of the career through poverty reduction.

\section{Barriers in TEVT}

There are several barriers in getting technical education. The notion of technical education and vocational training is to provide the skill to the needy people for economic development. There are several barriers in the TEVT sector. Adequate funds, access to the resources, environment, inclusion, job placement are some of the major concerns of the TEVT.

The main barrier in the TEVT sector is the fund. Adequate fund is not provided to this sector; so mainstreaming TEVT has been one of the problems. The technical equipment and the infrastructure are so expensive that it causes financial constraints to develop TEVT in the national development. Apart from this, technical experts are also not in adequate number. Nepal now needs good quality technologists trained by university, technical colleges and polytechnics (Sharma, 2013). This also highlights that there is need of the technical experts to sustain and provide quality TEVT. There is the urgent need of the investors to make this system a good platform to produce entrepreneurs. Similarly, access is also one of the main barriers to the TEVT sector. The disadvantaged, women, marginalized people and those who are out of the mainstream of the development are still not getting the ample access to join the TEVT sector. Also the inclusion of those groups is one of the issues in this sector. Though there are plans and policies regarding the inclusion of those communities, the adequate platform for the inclusion is still lacking.

Not only this, there is also the major challenge of social and gender inclusion in TEVT. Gurung (2010) also highlights that the indigenous people, women, madhesi, dalits and other religious minorities are normally excluded from the mainstream of development and they are lacking the socio economical opportunities. So the inclusion has become one of the challenging agendas. There are social and religious constraints in the society. So it has been difficult to eliminate the deep rooted social beliefs and culture in this context. Moreover the inclusion plans, quota systems etc are some of the achievements but still the implementation and participation are not being effective.

Likewise, job placement is another barrier in the mainstreaming of TEVT. The main aspect of technical education is to provide employment rather being self employed. But there are so many challenges and hindrances ahead. Student with the certificates are in search of good job. If the various barriers are solved then TEVT would really help for the sustainable development of a nation. Also another barrier is mismatch between the production and job market. The demand of the job market is different than the product of TEVT. It has made complications to compete in the job market.

If we see the focuses of UN Millennium Development Goals (MDG), education is more prioritized on basic and especially on the universal primary education. The focus neglects post-basic education and training including technical and vocational education and training (TVET) (Fluitman 2005 as cited in Onderi, Ajowi and Malala, 2014). This is also one of the basic factors on how the plans and policies are neglecting the TEVT sector.

\section{Conclusions}

TEVT in developing countries plays a vital role in the overall development of the nation. It plays crucial role in the National Sustainable Development. The first role is to provide training opportunities and 
career advancements for the students who don't want to continue the general education and it will also help to minimize drop out children and out of the school children. Similarly, it will help to provide skill human resources needed at all levels of the national economy.

Government should provide adequate fund to support polytechnic and technical schools to ensure that facilities are provided and maintained. There is the necessity of Polytechnic University to provide technical education and vocational training. The government in partnership with the vocational educators should create awareness on the significance of vocational education to individuals through workshops, seminars and conferences. There should be adequate emphasis on practical aspect of vocational education to facilitate the recipients to acquire skills and reduce the over dependence on government paid jobs. Also a clear articulation of the possible pathways between different sectors and TEVT should work together to develop a whole person that has Sustainable Development values, ethics, knowledge, attitudes and skills to contribute to a sustainable future. Only ensuring the attitude of the people on TEVT sector about its importance can make TEVT a tool for sustainable development.

There is an urgent need to address the challenges of technical and vocational training to support economic development and the creation of national wealth and contribute to poverty eradication. It is very effective and essential in terms of the developing countries like Nepal for the sustainability. For the sustainability of the TEVT and competitive market, TVET system must be labor-market relevant, equitable, efficient, and of high quality. So creating a secure economic environment that promotes the growth of enterprises and generally stimulates the economy is the demand of the financing agencies too. This should be taken in consideration for the betterment of TEVT. So the main purpose of TEVT is to provide skills, knowledge as per the market demand so that there will be secured job and TEVT will help to promote competitive entrepreneurship as per the demand of the job market.

\section{References}

Adebola, H.E (2007). Standard in Mass literacy. Adult and NonFormal Educatoin. Capacity Building and Sustainable Development in Nigeria. UNIZIK Orient Journal of Education. 3(1). $129-133$.

Alam, G.M. (2007). Private Higher Education in Bangladesh: the impact on Higher Education, governance \& legislation. Unpublished $\mathrm{PhD}$ thesis, University of Nottingham, United Kingdom.

Chinwe, M. O (2008). Nigeria Imperative for Youth Led Entrepreneurial Development. Centre for International private Enterprise. U.S.A Chamber of commerce.

Gurung, O. (2010). Social inclusion: policies and practices in Nepal. Retrieved from http://nepjol. info/index.php/OPSA/article/view/3027/2628 http://mcserorg.ervinhatibi.com/journal/index. php/jesr/article/download/436/453

Immaculate, E.E (2005). The funding needs of vocational and technical education programmes in Nigeria school system.JONATT 5 (1) 18 - 21.

N.U. Alhasan \& T. Abdullahi (2013). Revitalizing Technical and Vocational Education (TEVT) for youth empowerment and sustainable development. Journal of Education and Social Science Research. Retrieved from

Okoro, O.M (1993), Principles and Methods of Vocational and Technical Education, Nsukka: University Trust Publisher.

Onderi, H., Ajowi, J.\& Malala, G.( 2014). Restructuring Technical and Vocational Education and Training (TVET) For Sustainable Development in Sub-Saharan Africa. Internationalb Journal of Interdisciplinary Research and Innovations. Retrieved from http://www.researchpublish.com/download. php? file=RESTR U C T UR IN G \% 20 
TECHNICAL\%20AND\%20VOCATIONAL $\% 20$ EDUCATION-123.pdf\&act=book

Sharma, S.R. (2013). Empowering youths with skills.

Technical and Vocational Education and Training Development Journal. Retrieved from http://ctevt.org.np/files/Research\%20Journal \%202013.pdf

UNESCO. (2004). Synthesis report: Improving access, equity and relevance in technical vocational education and training (TVET). Bangkok, Thailand: UNESCO. 